\title{
Monitoring pojave američkog cvrčka (Scaphoideus titanus) i fitoplazme vinove loze (Flavescence dorée) na lokalitetu Ilok, 2018. godine
}

\section{Sažetak}

Američki cvrčak (Scaphoideus titanus Ball.) jedini je poznati prirodni vektor zlatne žutice vinove loze. Hrani se sišući sokove iz floema vinove loze, pri čemu usvaja fitoplazmu (Flavescence dorée) koju unosi u svoj organizam i na taj način ju prenosi hranjenjem sa zaraženih na zdrave trsove. Za uspješno suzbijanje američkog cvrčka vrlo je bitno poznavati njegovu biologiju i ekologiju. Temeljem toga cilj ovog rada bio je istražiti prisutnost i utvrditi brojnost američkog cvrčka, te učinkovitost tretiranja. Istraživanje je postavljeno 2018. godine na lokalitetu llok. Pratila se dinamika pojave i utvrdila se brojnost ličinki i odraslih oblika američkog curčka u vinogradima na tri različite lokacije u lloku. Dinamika pojave i brojnost pratila se uz pomoć žutih ljepljivih ploča. Istraživanje je pokazalo da je prosječan ulov po žutoj ploči bio 2, 5 ili 9 američkih cvrčaka, ovisno o lokalitetu. Učinkovitost tretiranja pokazala se najuspješnijom u vinogradu na lokaciji "Principovac", u kojemu su korištena zaštitna sredstva različitih skupina prema mehanizmu djelovanja. U istraživanju nisu utvrđeni simptomi zlatne žutice vinove loze.

Ključne riječi: američki curčak, vinova loza, zlatna žutica vinove loze, dinamika

\section{Uvod}

Zlatna žutica vinove loze najopasnija je i najdestruktivnija bolest vinove loze u Europi, a pripada skupini žutica vinove loze. U Republici Hrvatskoj je 2009. godine potvrđen prvi nalaz zlatne žutice vinove loze, te se od tada bilježi njezino širenje na većem dijelu teritorija Republike Hrvatske. Prema podacima i rezultatima laboratorijskih analiza pozitivni nalazi potvrđeni su u 11 županija (Koprivničko-križevačkoj, Bjelovarsko-bilogorskoj, Karlovačkoj, Vukovarskosrijemskoj, Virovitičko-podravskoj, Krapinsko-zagorskoj, Varaždinskoj, Međimurskoj, Zagrebačkoj, Istarskoj županiji i Gradu Zagrebu) (Kršić, 2018).

Zlatna žutica vinove loze je fitoplazmatska bolest čiji je uzročnik fitoplazma Flavescence dorée, a američki cvrčak (Scaphoideus titanus Ball.) primarni vektor koji epidemijski prenosi fitoplazmu od trećeg stadija ličinke do završetka životnog ciklusa odraslog oblika (Chuche i Thiéry, 2014). Godinu dana od nastanka infekcije razvijaju se simptomi zlatne žutice što može biti pod utjecajem različitih čimbenika poput varijabilne patogenosti fitoplazme, koncentracije fitoplazme u trsu, populacije vektora, osjetljivosti sorte i raznih abiotskih čimbenika (Caudwell, 1990). Vektor se hrani sišući sokove iz floema vinove loze, pri čemu usvaja fitoplazmu koju unosi u svoj organizam i prenosi je dalje hranjenjem na zdravim trsovima. Kada se uzročnici namnože do brojnosti koja začepljuje floem koji provodi hranjive tvari iz lišća u grozdove, drvo i korijen, pojavljuju se karakteristični simptomi žućenja lišća, uvijanja plojke prema naličju i sušenje cvata (Grozić i sur., 2018). Znatno smanjenje prinosa i propadanje zaraženih trsova glavne su štete uzrokovane zlatnom žuticom. U vinogradima gdje su istovremeno utvrđeni i prisutni štetni

Marina Marić, mag.ing.agr., studentica, Luka Poturiček, mag.ing.agr., student, Sveučilište Josipa Jurja Strossmayera u Osijeku,

Fakultet agrobiotehničkih znanosti Osijek,Vladimira Preloga 1, 31000 Osijek, Hrvatska

Josipa Puškarić, mag.ing.agr., prof.dr.sc. Emilija Raspudić, prof.dr.sc. KarolinaVrandečić, prof.dr.sc. Mirjana Brmež,

Sveučlišste Josipa Jurja Strossmayera u Osijeku, Fakultet agrobiotehničkih znanosti Osijek,Vladimira Preloga 1,31000 Osijek, Hrvatska

Autor za korespondenciju:kvrandecic@fazos.hr 
organizmi fitoplazme Flavescence dorée i prenositelj američki cvrčak nastupa epidemijsko širenje zlatne žutice. Unatoč tome što su mjere suzbijanja u svim europskim državama u kojima se uzgaja vinova loza propisane nacionalnim i regionalnim naredbama, zlatna žutica se i dalje širi u nova područja i zahtjeva stalno praćenje kako bi se utvrdila i spriječila nova područja zaraze. Svi posjednici vinove loze obvezni su pratiti prisutnost vektora zlatne žutice vinove loze, postavljanjem žutih ljepljivih ploča te suzbijati američkog cvrčka dopuštenim insekticidima. Budući da se jednom zaražen trs ne može izliječiti bitno je provođenje fitosanitarnih mjera $s$ ciljem iskorjenjivanja i sprječavanja širenja zlatne žutice (Grozić i sur., 2018).

Cilj ovog istraživanje bio je utvrditi eventualnu prisutnost američkog cvrčka i simptoma zlatne žutice vinove loze na lokalitetu Ilok. Za potrebe ovog rada postavljene su žute ljepljive ploče u svrhu praćenja prisutnosti američkog cvrčka na lokalitetu llok u vinogradima na tri različite lokacije. Na temelju analize žutih ljepljivih ploča u laboratoriju prikupljene su informacije o prisutnosti američkog cvrčka, vektora zlatne žutice vinove loze.

\section{Materijal i metode}

Istraživanje je provedeno na lokalitetu llok u vinogradima koji se prostiru na 3 lokacije:,,Principovac“, ,Lišćak“ i „Alvaluk“. U vinogradu na lokaciji,,Principovac“ uzgajaju se sorte Traminac i Rajnski rizling na površini od 2,01 ha. Vinograd je okružen drugim proizvodnim nasadima vinograda. $\mathrm{Na}$ predjelu „Lišćak“ smješten je drugi vinograd na kojem je provedeno istraživanje. U nasadu površine 2 ha zasađeno je 8000 trsova bijele vinske sorte Graševina. Vinograd se nalazi između nasada kukuruza i ekološkog uzgoja jabuka. Treći proizvodni vinograd nalazi se na lokaciji „Alvaluk“ smješten između nasada kukuruza i plantažnog nasada šljive. U vinogradu su zasađene sorte Graševina, Muškat Hamburg, Plemenka bijela i Slankamenka bijela na površini od 2,05 ha.

Praćenje imaga američkog cvrčka provedeno je primjenom žutih ljepljivih ploča postavljenih unutar vinograda od svibnja do rujna 2018. godine, kako bi se utvrdila učinkovitost provedenih insekticidnih tretiranja i pratio dolet imaga iz okoline. U svibnju 2018. godine prije tretiranja, te nakon svakog tretiranja vinove loze, postavljene su dvije žute ljepljive ploče na rubni i središnji dio vinograda. Kako bi se postigla veća učinkovitost praćenja američkog cvrčka i povećala vjerojatnost ulova, ploče su postavljene na najvišu ili srednju pomoćnu žicu unutar vegetacije ili u neposrednoj blizini lisne površine (Slika 1.).

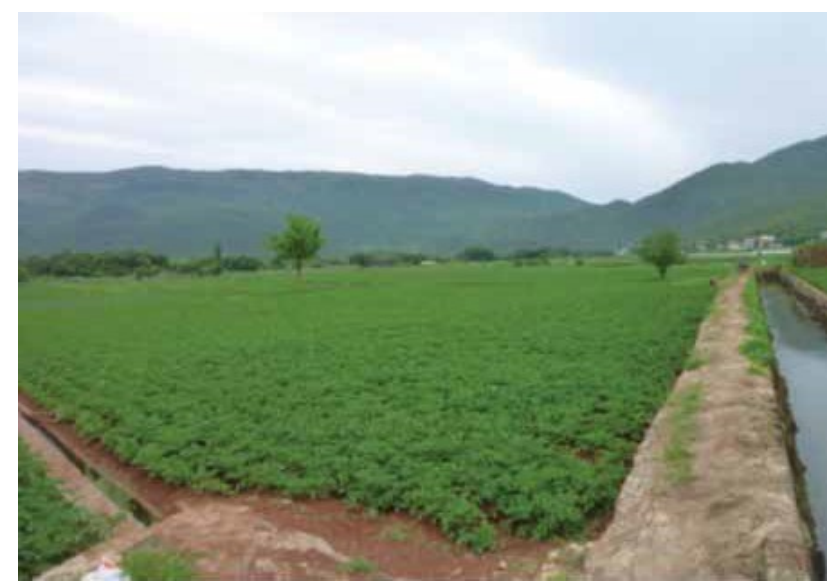

Slika 1. Postavljena žuta ljepljiva ploča na rubni (lijevo) i središnji dio vinograda (desno)

Figure 1. Placed yellow adhesive plate on the marginal (left) and central part of the vineyard(right) 
U vinogradima na Principovcu, Lišćaku i Alvaluku, tijekom 2018. godine tretiranje je obavljeno u 8 navrata, od travnja do kolovoza. Provedeno je suzbijanje četiri vrste štetnika: štitaste uši, lozine grinje, grozdovi moljci i cikade. Veći dio sredstava za zaštitu bilja korišten je pri suzbijanju uzročnika biljnih bolesti. Tablice 1., 2. i 3. prikazuju zaštitu vinove loze od američkog cvrčka, datum, zaštitna sredstva, djelatne tvari i djelovanje.

Tablica 1. Zaštita vinove loze od američkog cvrčka u vinogradu „Principovac“, 2018. godine

Table 1. Protecting vines from the Leafhopper in the vineyard „Principovac“, 2018.

\begin{tabular}{cccccc}
\hline $\begin{array}{c}\text { Redni broj/ } \\
\text { No. }\end{array}$ & $\begin{array}{c}\text { Vrijeme primjene/ } \\
\text { Application time }\end{array}$ & $\begin{array}{c}\text { Namjena tretiranja/ } \\
\text { Purpose of treatment }\end{array}$ & $\begin{array}{c}\text { Trgovački naziv sred- } \\
\text { stva/Trade name }\end{array}$ & $\begin{array}{c}\text { Djelatna tvar/ } \\
\text { Activesubstance }\end{array}$ & $\begin{array}{c}\text { Djelovanje/ } \\
\text { Impact }\end{array}$ \\
\hline 1. & 13.06 .2018$. & Cikade & Decis $2.5 \mathrm{EC}$ & $\begin{array}{c}\text { Deltametrin } \\
2,5 \%\end{array}$ & Kontaktno \\
\hline 2. & 27.06 .2018$. & Cikade & Actara 25 WG & $\begin{array}{c}\text { Tiametoksam } \\
25 \%\end{array}$ & Sistemično \\
\hline 3. & 17.07 .2018$. & Cikade & Sumialfa 5 FL & Esfenvalerat 50 \% Kontaktno \\
\hline
\end{tabular}

Tablica 2. Zaštita vinove loze od američkog cvrčka u vinogradu „Lišćak“, 2018. godine

Table 2. Protecting vines from the Leafhopper in the vineyard „Lišćak“, 2018.

\begin{tabular}{cccccc}
\hline $\begin{array}{c}\text { Redni broj/ } \\
\text { No. }\end{array}$ & $\begin{array}{c}\text { Vrijeme primjene/ } \\
\text { Application time }\end{array}$ & $\begin{array}{c}\text { Namjena tretiranja/ } \\
\text { Purpose of treatment }\end{array}$ & $\begin{array}{c}\text { Trgovački naziv sred- } \\
\text { stva/Trade name }\end{array}$ & $\begin{array}{c}\text { Djelatna tvar/ } \\
\text { Activesubstance }\end{array}$ & $\begin{array}{c}\text { Djelovanje/ } \\
\text { Impact }\end{array}$ \\
\hline 1. & 10.06 .2018$. & Cikade & Chromorel-D & $\begin{array}{c}\text { Klorpirifos } 50 \%+ \\
\text { cipermetrin } 5 \%\end{array}$ & $\begin{array}{c}\text { Kontaktno- } \\
\text { želučano }\end{array}$ \\
\hline 2. & 03.07 .2018$. & Cikade & Decis $2.5 \mathrm{EC}$ & $\begin{array}{c}\text { Deltametrin } \\
2,5 \%\end{array}$ & Kontaktno \\
\hline 3. & 05.08 .2018$. & Cikade & Sumialfa 5 FL & Esfenvalerat $50 \%$ & Kontaktno \\
\hline \hline
\end{tabular}

Tablica 3. Zaštita vinove loze od američkog cvrčka u vinogradu „Alvaluk“, 2018. godine

Table 3. Protecting vines from the Leafhopper in the vineyard „Alvaluk“, 2018.

\begin{tabular}{|c|c|c|c|c|c|}
\hline $\begin{array}{l}\text { Redni broj/ } \\
\text { No. }\end{array}$ & $\begin{array}{l}\text { Vrijeme primjene/ } \\
\text { Application time }\end{array}$ & $\begin{array}{c}\text { Namjena tretiranja/ } \\
\text { Purpose of tre- } \\
\text { atment }\end{array}$ & $\begin{array}{l}\text { Trgovački naziv sred- } \\
\text { stva/Trade name }\end{array}$ & $\begin{array}{l}\text { Djelatna tvar/ } \\
\text { Active substance }\end{array}$ & $\begin{array}{l}\text { Djelovanje/ } \\
\text { Impact }\end{array}$ \\
\hline 1. & 10.06.2018. & Cikade & Sumialfa $5 \mathrm{FL}$ & Esfenvalerat $50 \%$ & Kontaktno \\
\hline 2. & 05.07.2018. & Cikade & Decis $2.5 \mathrm{EC}$ & Deltametrin 2,5 \% & Kontaktno \\
\hline 3. & 03.08.2018. & cikade & Reldan $22 \mathrm{EC}$ & $\begin{array}{c}\text { Klorpirifos- metil } \\
22,5 \%\end{array}$ & $\begin{array}{c}\text { Kontaktno- } \\
\text { želučano }\end{array}$ \\
\hline
\end{tabular}

U vinogradu na lokaciji „Principovac“ prvi par žutih ljepljivih ploča postavljen je 15. svibnja 2018. godine, a skinut i analiziran 05. lipnja, te su istoga dana postavljene druge dvije žute ploče, koje su skinute i analizirane 20. lipnja. Treće žute ploče postavljene su 20. lipnja, skinute su i pregledane 04. srpnja, nakon čega su istoga dana postavljene četvrte žute ploče. Posljednji par žutih ploča skinut je i pregledan 24. srpnja 2018. godine. U vinogradu na lokaciji „Lišćak“ prve dvije žute ploče postavljene su 15. svibnja 2018. godine koje su 05. lipnja skinute i pregledane, te zamjenjene novim parom žutih ploča. Nadalje, drugi par ploča skinut je i pregledan 
17.lipnja, te su istoga dana postavljene nove dvije ploče koje su skinute i pregledane 10. srpnja. Posljednji par žutih ploča postavljen je 10. srpnja, a skinut i analiziran 12. kolovoza 2018. godine. U trećem vinogradu, smještenom na lokaciji „Alvaluk“, prve žute ploče postavljene su 15. svibnja, a skinute i analizirane 05. lipnja 2018. godine. Drugi par žutih ploča postavljen je 05 . lipnja, skinut i pregledan 17. lipnja, te je postavljen treći par žutih ploča koji je skinut i analiziran 12. srpnja. Četvrti par žutih ploča postavljen je 12. srpnja, te je skinut i pregledan sedam dana nakon trećeg tretiranja, odnosno 10. kolovoza 2018. godine.

Žute ploče su na svim lokalitetima skidane i pregledane 7 dana nakon svakog tretiranja. Redovito je praćeno stanje kroz sve razvojne stadije vinove loze obilaskom vinograda, zamjenom i pregledom žutih ljepljivih ploča. Nakon prikupljanja, ploče su umotane u prozirnu kuhinjsku foliju te su naznačeni svi potrebni podatci o lokaciji i datumu prikupljanja. Determinacija američkog cvrčka provođena je vizualnim pregledom žutih ljepljivih ploča uz pomoć povećala i svjetlosnog mikroskopa u Centralnom laboratoriju za fitomedicinu, u laboratoriju za entomologiju Fakulteta agrobiotehničkih znanosti Osijek (Slika 2.). U tu svrhu vođena je i evidencija o zaštiti vinograda od bolesti i štetnika.

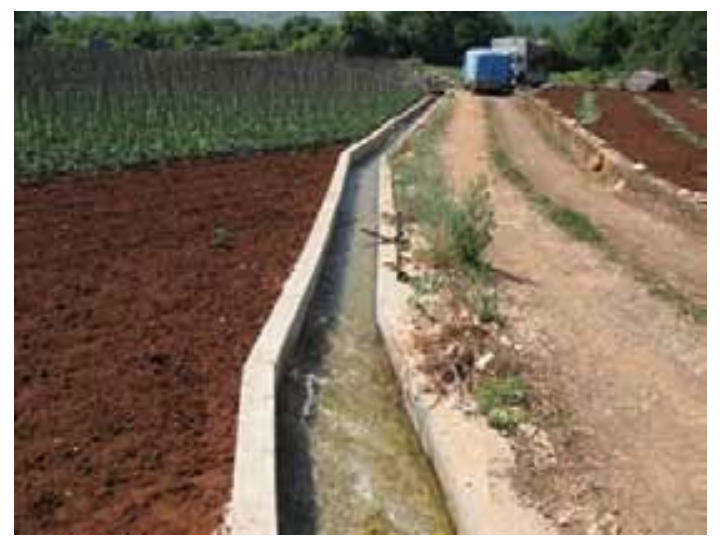

Slika 2. Pregled žutih ljepljivih ploča uz pomoć povećala

Figure 2. Overview of yellow adhesive panels with magnifier

\section{Rezultati i rasprava}

Vinograd na lokaciji,,Principovac"

U vinogradu na lokaciji „Principovac“ utvrđeno je ukupno 20 ličinki američkog cvrčka, prije bilo kakvog tretiranja vinove loze u svrhu zaštite od američkog cvrčka. Nakon prvog tretiranja, ploča postavljena na rubnom dijelu vinograda brojala je 10 ličinki, a ploča u sredini vinograda 4 ličinke američkog cvrčka. Nakon svakog idućeg tretiranja, uočava se pad broja ličinki i odraslog oblika američkog cvrčka. Prosječno je po žutoj ljepljivoj ploči ulovljeno 2 američka cvrčka. U grafikonu 1. prikazan je odnos ličinki i odraslog oblika američkog cvrčka prije i nakon svakog tretiranja. 


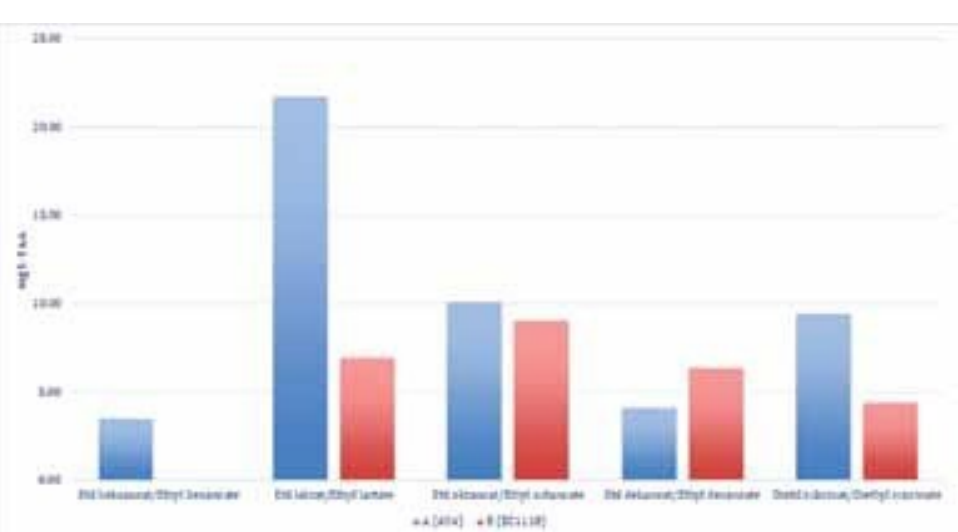

Grafikon 1. Broj ličinki i odraslog oblika američkog cvrčka prije i nakon tretiranja u vinogradu na lokaciji,,Principovac"

Graph 1. Number of larvae and adult form of the Leafhopper before and after treatments in the vineyard at Principovac

Na ovakvo zatečeno stanje američkog cvrčka mogao je utjecati povoljan smještaj vinograda, udaljenost šuma i zapuštenih vinograda te suzbijanje pepeljastog grozdovog moljca i lozinog zelenog cvrčka, budući da je istraživanjem na području Istarske županije dokazano da izostanak suzbijanja štetnika vinove loze doprinosi razvoju visoke populacije američkog cvrčka (Grozić i sur., 2018.).

\section{Vinograd na lokaciji,,Lišćak“}

U vinogradu na lokaciji,„Lišćak“ utvrđeno je ukupno 91 ličinka, prije prvog tretiranja. Nakon prvog tretiranja na žutim ljepljivim pločama koje su bile postavljene na rubni i središnji dio vinograda utvrđeno je ukupno 76 ličinki američkog cvrčka. Broj ličinki se nakon drugog tretiranja smanjio na 8 odraslih oblika i 3 ličinke, no nakon trećeg je utvrđeno ukupno 44 odrasla oblika američkog cvrčka i jedna ličinka (Grafikon 2.). Po žutoj ljepljivoj ploči, prosječno je ulovljeno 9 američkih cvrčaka.

\section{Vinograd "Lišćak"}

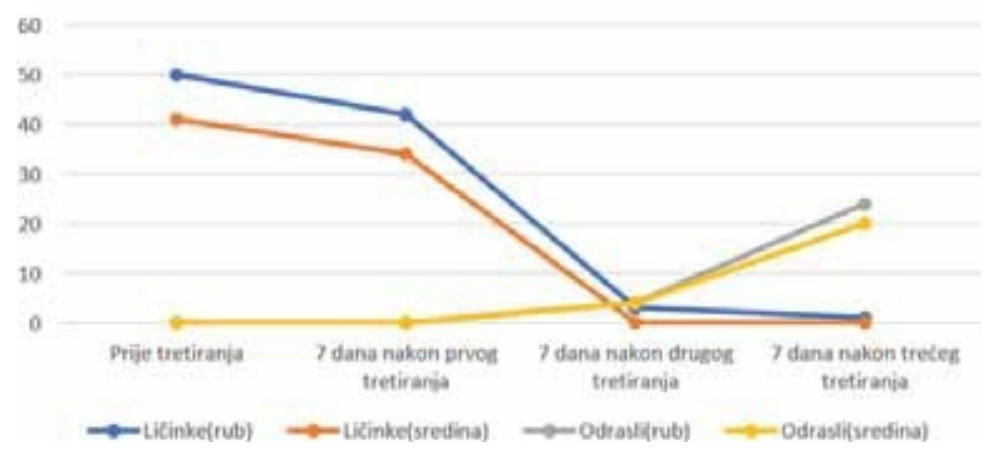

Grafikon 2. Broj ličinki i odraslog oblika američkog cvrčka prije i nakon tretiranja u vinogradu na lokaciji,„Lišćak"

Graph 2. Number of larvae and adult form of the Leafhopper before and after treatments in the vineyard at Lišćak 
Zaštitna sredstva korištena u tretiranju pripadaju u istu skupinu prema mehanizmu djelovanja, te je to mogao biti razlog velikog ulova imaga nakon posljednjeg tretiranja. Nadalje, razlozi velikog broja ulova američkog cvrčka na žutim ljepljivim pločama mogu biti uvjetovani i razlikama u ekološkim uvjetima koji su prisutni unutar vinograda, kao što su temperatura, vlaga, blizina šume, itd. (Posenato i sur., 2001.).

\section{Vinograd na lokaciji,,Alvaluk“}

U vinogradu na lokaciji „Alvaluk“ utvrđeno je ukupno 51 ličinka na dvije žute ploče uoči prvog tretiranja. Nakon prvog tretiranja broj ličinki smanjio se na 33, dok je nakon drugog tretiranja utvrđeno ukupno 29 ličinke i 13 odraslih oblika američkog cvrčka. Pregledom ploča 7 dana nakon trećeg tretiranja, utvrđeno je 4 odrasla oblika američkog cvrčka na dvije žute ljepljive ploče (Grafikon 3.). Prosječno po žutoj ljepljivoj ploči ulovljeno je 5 američkih cvrčaka.

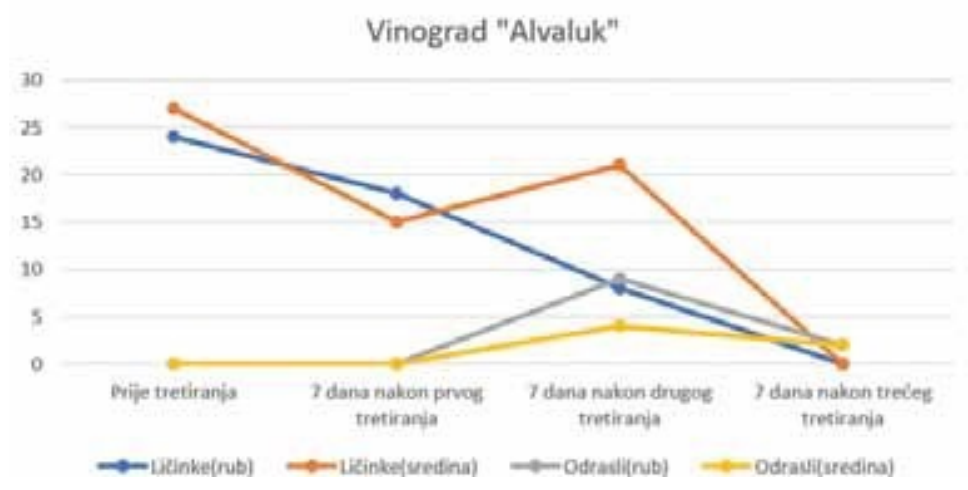

Grafikon 3. Broj ličinki i odraslog oblika američkog cvrčka prije i nakon tretiranja u vinogradu na lokaciji,,Alvaluk“

Graph 3. Number of larvae and adult form of the Leafhopper before and after treatments in the vineyard at Alvaluk

Razlog lošeg rezultata prva dva tretiranja može biti zbog iste pripadajuće skupine prema mehanizmu djelovanja, budući da se za veću učinkovitost preporuča koristiti zaštitna sredstva različitih skupina. Najučinkovitijim pokazao se kontaktno-želučani insekticid Reldan 22 EC nakon čije je aplikacije uhvaćeno 4 odrasla oblika američkog cvrčka na cijeloj površini vinograda.

\section{Zaključak}

Zlatna žutica je bolest vinove loze i ako se ne suzbija na prikladan način, može se brzo širiti i uzrokovati znatne ekonomske gubitke u vinogradarsko-vinarskom sektoru. Najučinkovitije se suzbija ako se provodi suzbijanje američkog cvrčka u kombinaciji s uklanjanjem simptomatičnih trsova iz vinograda u što kraćem roku nakon prve pojave simptoma. U područjima u kojima zaraza još uvijek nije uočena, pregledom vinograda može se spriječiti ili usporiti širenje vektora. Ukoliko je američki cvrčak prisutan u visokoj populaciji u vinogradu, svega jedan zaražen trs može uzrokovati epidemijsko širenje zlatne žutice.

Istraživanje je provedeno na lokalitetu Ilok, u vinogradima na 3 različite lokacije („Principovac“, „Lišćak“ i „Alvaluk“) u kojima se tretiranja protiv američkog cvrčka provode tri puta godišnje, uz vizualan pregled trsova te postavljanje žutih ljepljivih ploča.

U vinogradu na lokaciji „Principovac“ prosječan ulov po žutoj ljepljivoj ploči je 2 američ- 
ka cvrčka. Primijenjeni tretmani zaštitnim sredstvima, obavljeni u tri navrata, pokazali su se uspješnim u suzbijanju populacije američkog cvrčka.

U vinogradu na lokaciji „Lišćak“, prosječno je ulovljeno 9 američkih cvrčaka po žutoj ljepljivoj ploči, što je ujedno i najveća prosječna populacija ulovljena u sva tri vinograda. Tretiranja obavljena u tri navrata nisu se pokazala učinkovita, budući da dva od tri korištena zaštitna sredstva pripadaju istoj skupini prema mehanizmu djelovanja.

U vinogradu na lokaciji „Alvaluk“ prosječna populacija je 5 američkih cvrčaka po žutoj ljepljivoj ploči. Prva dva tretiranja u svrhu zaštite vinove loze od američkog cvrčka nisu pokazala učinkovitost u odnosu na treće tretiranje.

Podizanje razine svijesti vinogradara i rasadničara o važnosti suzbijanja američkog cvrčka, edukacija o epidemiologiji zlatne žutice, simptomima i riziku kojeg ona predstavlja, bitno je u svrhu prevencije daljnjeg širenja ove bolesti.

\title{
Napomena
}

Rad je proizašao iz diplomskog rada „Monitoring pojave američkog cvrčka (Scaphoideus titanus) i fitoplazme vinove loze (Flavescence dorée) na lokalitetu llok, 2018. godine“ autorice Marine Marić, mag. ing. agr. obranjenog na Fakultetu agrobiotehničkih znanosti.

\section{Literatura}

Caudwell, A. (1990) Epidemiology and characterization of Flavescence dorée (FD) and other grapevine yellows. Agronomie, 10 (8), 655-663.

Chuche, J., Thiéry, D. (2014) Biology and ecology of the Flavescence dorée vector Scaphoideus titanus: a review. Agronomy for Sustainable Development, 34 (2), 381-403.

Grozić, K., Bubola, M., Poljuha, D. (2018) Pregled simptoma, epidemiologije i mjera za sprječavanje širenja zlatne žutice vinove loze u nezaražena područja. Glasnik zaštite bilja. 3/2018, 50-58.

Grozić, K., Poljuha, D., Bubola, M. (2018) Suzbijanje zlatne žutice vinove loze: smanjenje šteta i sprječavanje širenja zaraze. Glasnik zaštite bilja 4/2018, 32-38.

Kršić, M. (2018) Zlatna žutica vinove loze. Hrvatska poljoprivredno-šumarska savjetodavna služba.

Posenato, G., Mori, N., Bressan, A., Girolami, V., Sancassani, G.P. (2001) Scaphoideus titanus, vettore della flavescenza dorata: conoscerlo per combatterlo. Linformatore agrario, 15, 91-94.

Prispjelo/Received: 11.2.2020.

Prihvaćeno/Accepted: 10.3.2020.

\section{Original scientific paper}

\section{Monitoring of leafhopper on grapevine (Scaphoideus titanus) and Flavescence dorée phytoplasma in vineyards of Ilok, in year 2018}

\begin{abstract}
Leafhopper (Scaphoideus titanus) is the only known natural vector of golden grapevine yellow. It feeds by sucking juice from the grapevine, receiving Flavescence dorée, which enters into its own organism and thus it transmitting by feeding from infected to healthy stock. For successfully control of leafhopper, it is very important to know it's biology and ecology. Based on that the aim of this paper was to investigate the presence and determine the number of leafhoppers and treatments efficiency.

The research was set up in 2018 at the llok site. The dynamics of the appearance and the number of larval and adult forms of leafhopper in vineyards were determined at three different locations. Dynamics of both elements was assessed by yellow adhesive plates. The study showed that the average catch per yellow adhesive plate was 2, 5 or 9 leafhoppers depending on the location. The most effective treatment was in the vineyard at the Principovac site, which included protective agents of different groups according to the mechanism of activity. In this study no symptoms of golden grapevine yellow were found.

Key words: leafhopper, grapevine, golden yellow grapevine, the dynamics
\end{abstract}

